\title{
Interventional treatment options in pseudoaneurysms: different techniques in different localizations
}

\author{
Orkun Sarioglu ${ }^{A, B, D, E, F}$, Ahmet Ergin Capar ${ }^{B, D, F}$, Umit Belet $^{\mathrm{A}, \mathrm{F}}$ \\ Department of Radiology, Health Sciences University, Tepecik Educational and Research Hospital, Izmir, Turkey
}

\begin{abstract}
Pseudoaneurysms are commonly experienced vascular abnormalities. The increase in the number of surgical and arteriographic procedures has caused a higher prevalence of pseudoaneurysms. Conventional angiography is still the gold standard method for diagnosis, but other imaging modalities such as duplex Doppler ultrasonography, magnetic resonance angiography and computed tomographic angiography are useful in noninvasive detection. Over the past few years, interventional radiological treatment has evolved and taken the place of surgery in management. There are different kinds of percutaneous and endovascular treatment methods in pseudoaneurysm management. Treatment options depend on certain conditions. We used a case-based approach to discuss pseudoaneurysms and their appropriate treatment by interventional radiological methods in this article.
\end{abstract}

Key words: pseudoaneurysm, endovascular procedure, interventional radiology.

\section{Introduction}

Pseudoaneurysms are common vascular abnormalities that occur from a defect in the arterial wall. Blood leaks through the disrupted wall into the surrounding tissue, which leads to a persistent communication between the originating artery and the adjacent cavity. Pseudoaneurysms have a variety of causes, such as inflammation, trauma, and various iatrogenic causes such as surgery, percutaneous biopsy, drainage, and postcatheterization [1]. Pseudoaneurysms may occur in any damaged vessel including the carotid, extremity and visceral arteries.

Conventional angiography is still the gold standard method for diagnosis [2], but other imaging modalities such as duplex Doppler ultrasonography (US), magnetic resonance (MR) angiography and computed tomographic (CT) angiography are effective in noninvasive detection. Early diagnosis is essential when considering the ruinous consequences of pseudoaneurysms.

In recent years percutaneous endovascular and surgical approaches for the treatment of arterial disease have been multiplying. These increased procedures and modern imaging modalities have made the diagnosis of pseudoaneurysms more common [3]. Up until a short time ago, surgical repair had been the primary treatment option. Over the past few years, interventional radiological treatment has evolved and taken the place of surgery [4,5]. The aims of this article are to review the minimally invasive treatment techniques of pseudoaneurysms and to discuss appropriate selection of the treatment option considering the features of the lesion.

\section{Epidemiology}

Formerly, the reported incidence of postcatheterization pseudoaneurysms ranged from $0.05 \%$ to $2 \%[6,7]$. In these older retrospective studies, pseudoaneurysm diagnosis was made by clinical examination. Also, percutaneous endovascular techniques were less common in the past. Nowadays, minimally invasive treatment techniques are being used for many diseases. The increasing use of large-sized catheters and periprocedural anticoagulation

\footnotetext{
Correspondence address:

Dr. Orkun Sarioglu, Department of Radiology, Health Sciences University, Tepecik Educational and Research Hospital, 1140/1 Street, 35180, Yenisehir, Izmir,

Turkey, e-mail: orkunsarioglu@gmail.com
}

Authors' contribution:

A Study design · B Data collection · C Statistical analysis · D Data interpretation · E Manuscript preparation · F Literature search · G Funds collection 
and antiplatelet therapy has caused higher incidence of pseudoaneurysms [3]. Furthermore, modern imaging modalities including US, duplex Doppler US, MR angiography and CT angiography have helped detecting the pseudoaneurysms easily. In recent studies, postprocedural groin pseudoaneurysm incidence was reported as 2-6\% [8] In comparison to femoral artery pseudoaneurysms, visceral artery pseudoaneurysm are rare but life-threatening conditions [9]. The incidence of renal pseudoaneurysms is $0.01-0.09 \%$ and that of splanchnic pseudoaneurysms is $0.1-2 \%$ [10]. Pseudoaneurysms may arise from any vessel affected by inflammation or trauma.

\section{Clinical features}

Pseudoaneurysms may not always show clinical findings and may be noticed during a radiological examination performed for another reason. Symptoms of pseudoaneurysms vary depending on their location. The most common presentation of a femoral artery pseudoaneurysm is the presence of a pulsatile mass or palpable thrill with pain. Complications of pseudoaneurysms may be the result of mass effect and compression to the adjacent structures. During the follow-up period or if the pseudoaneurysm is not recognized, spontaneous thrombosis may occur [11] or serious complications may develop.

Local ischemia, critical limb ischemia, skin necrosis, neuropathy, venous thrombosis and infection are the main complications $[12,13]$. Apart from these, rupture is the most important and dangerous complication because of the risk of morbidity and mortality $[14,15]$. Ruptured visceral pseudoaneurysms have higher mortality rates of $25-70 \%$ depending on the diameter and the location [16]. Rupture and active extravasation from the pseudoaneurysm may manifest as bleeding from a drain, hematemesis, melena, subcapsular hepatic or splenic hematoma.

\section{Imaging}

\section{Ultrasonography}

US is a useful, easy, cost-effective method and mostly the first choice in diagnosis of femoral artery pseudoaneurysms. A prospective study proved high sensitivity (94\%) and specificity (97\%) for the diagnosis of peripheral pseudoaneurysms by using duplex Doppler US [17]. B-mode US shows an anechoic or hypoechoic sac adjacent to the damaged artery (Figure 1A). The size and the neck of the pseudoaneurysm can be seen and measured with B-mode US. However, it is not always easy to demonstrate the communication between the originating artery and the sac with B-mode US. If the pseudoaneurysmal sac has a mural thrombus or hematoma inside, it can mimic complex cystic lesions or soft tissue hematomas. Duplex Doppler US supports the diagnosis by demonstrating arterial blood flow within the sac and the neck (Figure 1B). Blood flow is known as the characteristic "yin-yang" sign and spectral waveforms show to-and-fro flow pattern [18]. US is also useful in the treatment of pseudoaneurysms. US-guided compression and US-guided thrombin injection are highly recommended and used treatment methods for iatrogenic femoral artery pseudoaneurysms [8,19-21]. Despite all these advantages, US is not so effective in the assessment of visceral artery pseudoaneurysms or deep-located arteries. Moreover, the quality of this modality depends on the skills and experience of the operator.

\section{Computed tomographic angiography}

Multi-detector row helical CT scanners have evolved over the years and become a very important tool for the diagnosis of pseudoaneurysms. Contrast-enhanced helical
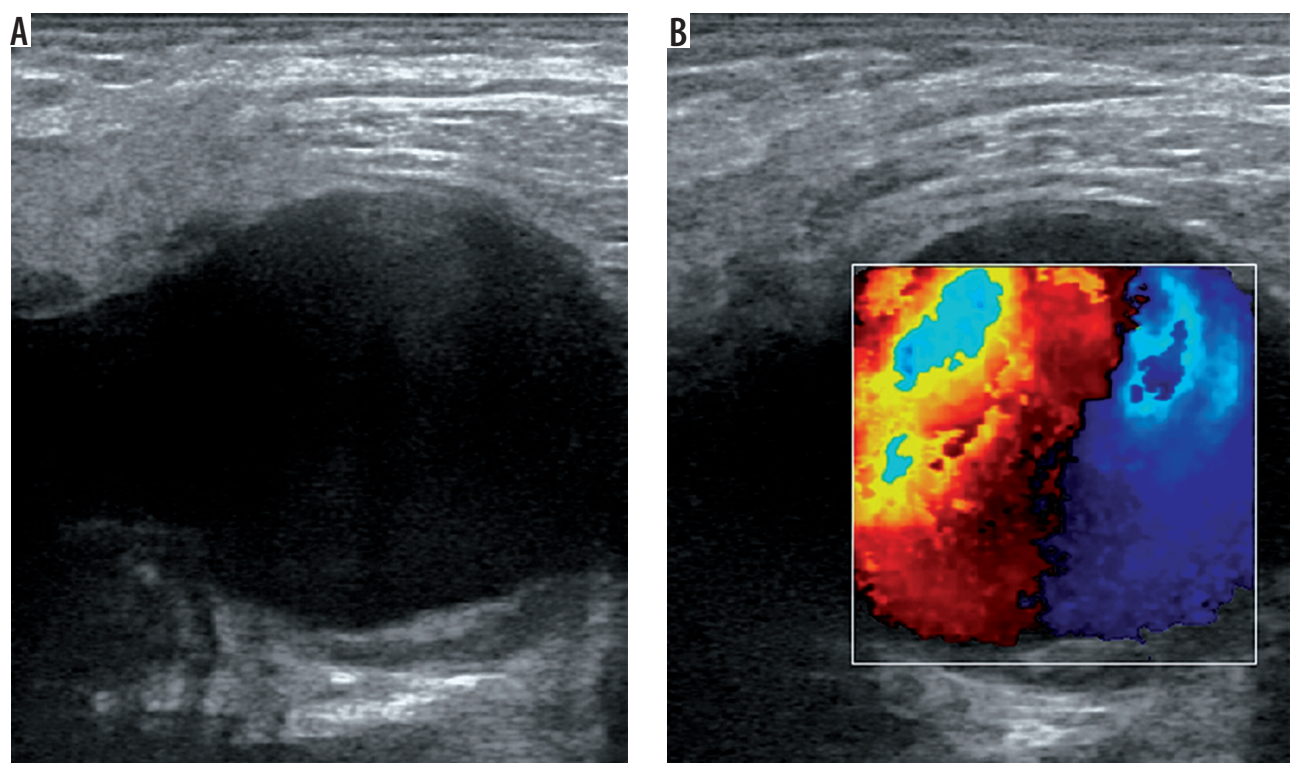

Figure 1. A) A hypoechoic sac is seen in B-mode ultrasonography. B) Duplex Doppler ultrasound demonstrates the "yin-yang" sign 
CT angiography has been reported as a convenient imaging modality in the detection of neck, chest, abdomen, pelvis and extremity pseudoaneurysms [22,23]. Unenhanced CT scans usually show a low-attenuated mass in contact with the damaged artery. Hemorrhage may be detected with intermediate or high attenuation adjacent to the pseudoaneurysm. Thrombosis can also be seen as high attenuation within the sac in unenhanced CT scans. After contrast enhancement, a pseudoaneurysm show up as a well-defined round or oval collection filled with contrast material (Figure 2). Persistent low-attenuated areas within the sac indicate partial thrombosis. High attenuation adjacent to the pseudoaneurysm reveals the most serious complication, rupture [24]. When compared to US, MR angiography and conventional angiography, CT angiography has some advantages. CT angiography is a standard method that is not dependent on the operator. CT angiographic images can be obtained in a couple of minutes. CT can also provide multiorgan screening of injured patients in trauma or reveal the cause of pseudoaneurysm such as pancreatitis. Although acquisition time is short in CT angiography (1-2 minutes), postprocessing of data usually takes some time (15 minutes) [25]. Despite this, three-dimensional CT angiography permits examination of the lesion and its neck from all angles [26]. Studies have reported high sensitivity of about $90 \%-95.1 \%$ and high specificity of about $98.7 \%-100 \%$ for the diagnosis of arterial injuries by using CT angiography [27,28]. Application of ionizing radiation and use of iodinated contrast material are disadvantages compared to MR angiography and US. Streak artifacts caused by foreign bodies and motion artifacts are the main problems in the assessment of vascular structures when using helical CT angiography. Conventional angiography is still the best method in detecting the damaged distal, small-caliber arteries with higher spatial resolution when compared to CT angiography [29]. Lastly, US guidance or conventional angiography allows treatment of pseudoaneurysm during diagnosis. CT angiography may only help planning the treatment.

\section{Magnetic resonance angiography}

MR angiography may be useful in patients with renal failure and a history of iodine allergy. Three-dimensional gadolinium-enhanced MR angiography demonstrates the pseudoaneurysm in axial, sagittal and coronal planes. However, use of MR imaging can be problematic, due to cost, availability, or patient conditions (e.g., pacemakers, claustrophobia). Moreover, especially in trauma patients, it is not convenient to choose the MR angiography modality because of the long acquisition time and MR-incompatible medical equipment. In addition, the presence of surgical clips or stents can cause artifacts that may disrupt the image quality and cause nondiagnostic results [30].

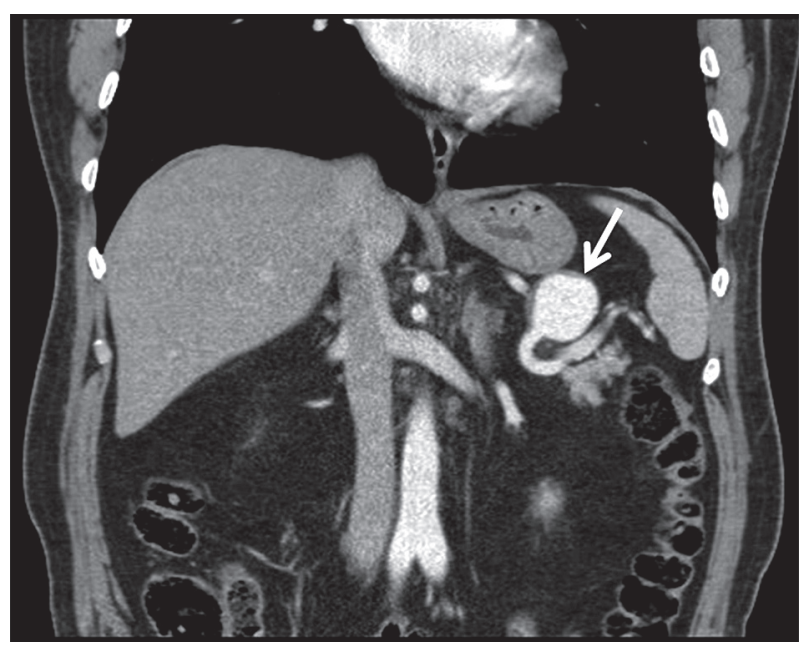

Figure 2. Coronal contrast-enhanced computed tomography shows a pseudoaneurysm that originates from the splenic artery

\section{Conventional angiography}

Conventional angiography continues to be the standard method for the diagnosis of pseudoaneurysm [1,2]. It is the best technique to demonstrate a pseudoaneurysm that cannot be seen in other imaging modalities such as US, CT and MR angiography. Furthermore, conventional angiography provides endovascular treatment options including embolization and stent-graft placement. Deciding on the appropriate treatment option for a pseudoaneurysm is an important issue. Angiography helps to solve this problem. Donor artery, the neck of the pseudoaneurysm, vascular supply, and collateral vascular structures can be evaluated with angiography. Sacrification of the donor artery and the treatment choice depend on these conditions. Despite these advantages, conventional angiography is an invasive procedure that may result in some complications such as hematomas, development of pseudoaneurysm, arteriovenous fistulas, thrombosis, distal embolization, arterial spasm, ischemia and intimal dissection [31]. The incidence of vascular complications was reported to be about $0.7-11.7 \%$ [32]. Pseudoaneurysm development after catheterization is between 0.5 and $2.0 \%$ and the risk increases up to $7.7 \%$ when coronary or peripheral interventions are performed [6,33]. In summary, conventional angiography can demonstrate small pseudoaneurysms and can help evaluating the hemodynamic condition of a vascular bed. Angiography should be performed when there is no evidence of a pseudoaneurysm in other imaging modalities but having a high suspicion clinically. Also, it is the first step in endovascular treatment procedures.

\section{Treatment}

As a general consensus, symptomatic pseudoaneurysms should be treated. On the other hand, it is a controversial issue that asymptomatic pseudoaneurysms should be treated or followed up. Depending on size and location, 
it is reported in the literature that some pseudoaneurysms may undergo spontaneous thrombosis $[11,34,35]$. The majority of small postcatheterization pseudoaneurysms result in spontaneous thrombosis without any medical procedure [36,37]. Based on these reports, conservative management may be recommended in asymptomatic iatrogenic femoral artery pseudoaneurysms. However, some departments prefer treating iatrogenic femoral artery pseudoaneurysms in case any complication occurs [8]. Although iatrogenic femoral artery pseudoaneurysms represent a large proportion of all pseudoaneurysms, visceral pseudoaneurysms are more aggressive and need to be taken more seriously apart from the size and symptoms. It should be borne in mind that the mortality rates of untreated ruptured visceral pseudoaneurysms may reach up to $100 \%[38,39]$.

Surgical repair was the first choice of treatment in pseudoaneurysms traditionally [40]. Reviewing the surgical techniques is outside the scope of this article. Basically, surgery involves a bypass procedure with resection, arterial ligation and visceral organ. Surgical treatment has some disadvantages such as long hospitalization time, requirement of general anesthesia and bad wound healing in patients with comorbidities. Furthermore, surgery has higher morbidity and mortality rates compared to interventional radiological treatment options [41]. The complications of surgery are bleeding, infection, lymphocele formation, radiculopathy, myocardial infarction, and death $[40,41]$. Over the past few years, with technolog-

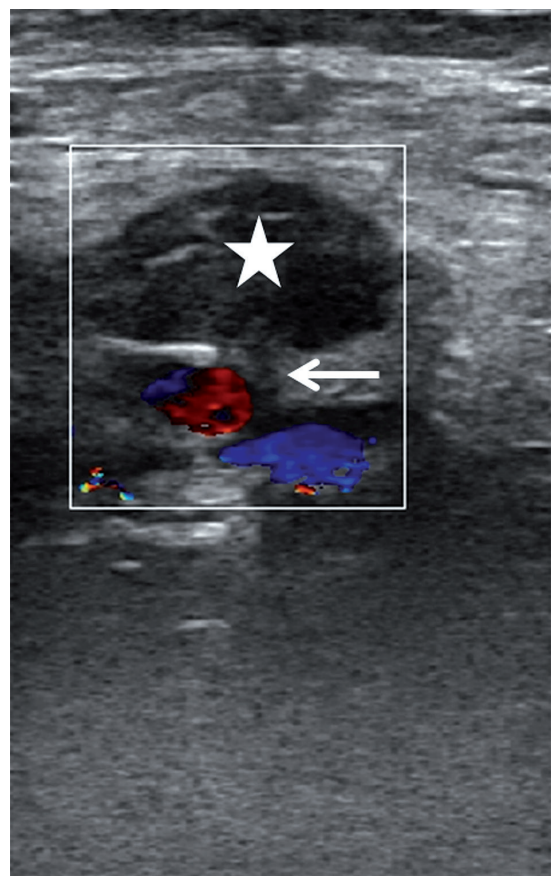

Figure 3. A 75-year-old woman who had undergone angiography 2 weeks ago was admitted with groin pain. A pseudoaneurysm of the common femoral artery was observed and treated with ultrasound-guided compression for about 30 minutes, until the pseudoaneurysm was totally excluded from the femoral artery due to the formation of a thrombus inside it (star). Note the neck of the pseudoaneurysm (arrow) ical development, interventional radiological treatment methods have taken the first place in the treatment of pseudoaneurysms. Nevertheless, surgery is still the gold standard treatment method in infected pseudoaneurysms, rapid growth, ischemia, neuropathy, and failure of percutaneous or endovascular treatment $[4,19]$.

\section{Ultrasound-guided compression}

US-guided compression is an easy, cost-effective, and safe technique in the management of postcatheterization femoral pseudoaneurysms. The successful thrombosis rate of the pseudoaneurysm has been reported as about 75-98\% $[42,43]$. This technique was the first choice in iatrogenic femoral artery pseudoaneurysms until recently. Ultrasound guidance allows one to observe the neck and the pseudoaneurysm during compression. Before compression, the location of the neck and the pseudoaneurysm should be assessed carefully. The US probe must be held over the neck and compression should cancel the flow through the neck and the pseudoaneurysm. However, pressure should allow the femoral artery to supply blood to the limb. If compression of the neck is not possible, US-guided compression can be done by compressing the pseudoaneurysm [44]. After 10-20 minutes, the pseudoaneurysm and peripheral pulses should be assessed with duplex Doppler US. If there is no flow within the neck and the sac, the procedure is considered successful and terminated (Figure 3 ). If there is still flow in the pseudoaneurysm, this procedure can be repeated three or four times up to 1 hour [45]. This technique can be used in superficially located arteries such as femoral, axillary and brachial.

US-guided compression is a difficult technique for both the patient and the operator. Compression is painful for the patient and intravenous sedation is needed mostly during the procedure. For the operator, it is difficult to hold the probe stationary and apply the same pressure for a long time. Factors that negatively affect the success of compression are anticoagulation status, pseudoaneurysm size (higher success rates for pseudoaneurysms less than $2 \mathrm{~cm}$ ) and obesity [4]. Complication rates of this method are reported to be about $2.4-4.3 \%$ in some studies $[20,43,46]$. Possible complications are rupture, skin necrosis, venous thrombosis and distal embolization. Infection, ischaemia and surgical grafts are contraindications of US-guided compression [13]. Lastly, compression is not suggested in pseudoaneurysms above the inguinal ligament due to the possibility of rupture.

\section{Percutaneous thrombin injection}

Thrombin, which is the active form of prothrombin, converts inactive fibrinogen into fibrin. Fibrin directly takes part in the formation of a thrombus. In recent years, numerous studies have demonstrated that ultrasound-guided percutaneous thrombin injection is a safe and useful 
method in postcatheterization pseudoaneurysms [47-49]. Since Kang et al. [50] described this procedure, it has been used commonly and taken the place of US-guided compression for the first treatment choice in postcatheterization pseudoaneurysms. With a high rate of thrombosis success, which is greater than $90 \%$ [51,52], this method is also practical because it is not as painful as compression and the procedure takes less time. Percutaneous management is favorable when endoluminal catheterization of the donor artery is not possible [5]. Pseudoaneurysms above the inguinal ligament can also be treated with this method. Many reports suggest using a concentration of 1000 IU/ $\mathrm{ml}[4,21,53]$. However, some centers recommend a lower concentration of $100 \mathrm{IU} / \mathrm{ml}$ [54]. Bovine thrombin or human thrombin can be used but bovine thrombin may cause allergic reactions. There are some reported cases of an anaphylactic reaction after injection of bovine thrombin [55]. Therefore, most operators prefer to use human thrombin.

US-guided thrombin injection technique is not complicated and generally there is no need for hospitalization. Before the injection, the pseudoaneurysm, the neck, and the adjacent structures are observed with a linear transducer. After that, a 19- to 22-gauge needle is advanced into the center of the pseudoaneurysm with US guidance. The injection is performed slowly and continually until the flow ends during duplex Doppler US monitoring (Figure 4). The flow in the sac usually stops within seconds. All these steps are carried out under sterile conditions. An additional dose should be injected similarly if there is still flow in the sac. Distal pulses are checked with duplex Doppler US after the procedure. Patients are monitored for about 4-6 hours and follow-up US should be performed after 24 hours.

The technical success rate was reported to be between $93 \%$ and $100 \%$ in studies conducted recently $[8,56,57]$. Complication rates of thrombin injection are below $4 \%$ $[48,49]$. Complications include distal embolization, urticaria or anaphylaxis, skin cellulitis or abscess formation, and rupture of the pseudoaneurysm. Local infection, distal ischemia, and a history of allergic reaction to thrombin are the main contraindications of this technique [53].

\section{Endovascular approach}

Endovascular management helps to eliminate the pseudoaneurysms from the circulation. There are two main methods in general practice: embolization [58] and stent placement [59]. When deciding on the best treatment option, the size of the neck and the collateral supplies of an end organ should be evaluated carefully [5]. If the artery is sacrificable and does not have any collateral supply, afferent artery embolization is performed (Figure 5). In these conditions, the embolization procedure can be done with coils [60], detachable balloons [61] or N-butyl 2-cyanoacrylate (glue) [1]. This is a useful procedure in arteries perfusing end organs (e.g. the kidney).

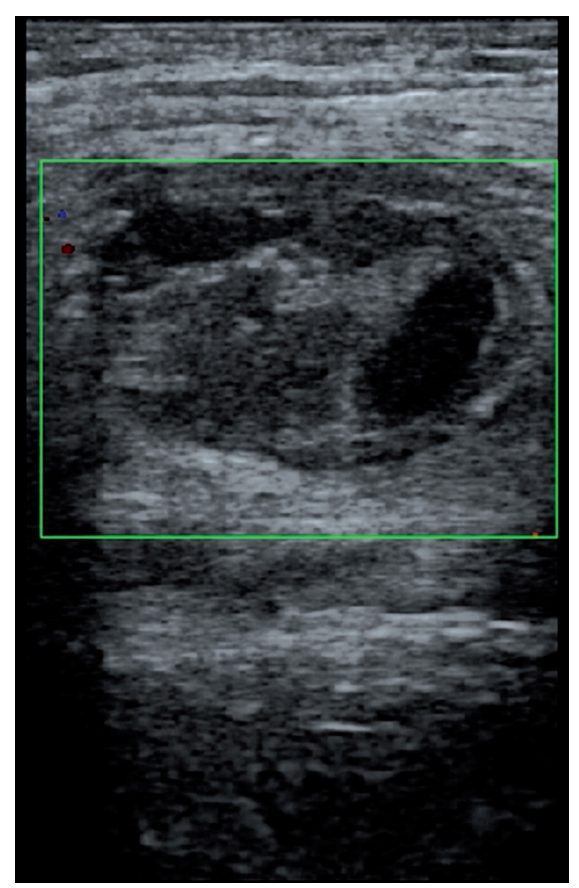

Figure 4. The pseudoaneurysm shown in Figure 1 was treated with percutaneous thrombin injection (1 $\mathrm{ml}$ )

The internal iliac artery and its branches and the distal extremity arteries usually have much collateral supply. If collaterals are seen in the angiogram, exclusion of the pseudoaneurysm is performed by means of distal and proximal coil embolization (Figure 6). Furthermore, various visceral arteries such as gastroduodenal, hepatic and splenic arteries also have a rich collateral network. Afferent and efferent artery occlusion is performed when treating these kinds of visceral arteries. Distal artery embolization and embolization of the pseudoaneurysm itself can be an alternative in appropriate conditions (Figure 7). These endovascular treatment methods are also used for the pseudoaneurysms (gastroduodenal, pancreaticoduodenal, or splenic artery) associated with chronic pancreatitis [62]. Due to the fact that chronic pancreatitis is a continuous inflammation, surgical approaches are suggested after endovascular embolization to avoid rebleeding [63]. However, it was concluded in recent studies that endovascular embolization is the first choice and an effective method in patients with chronic pancreatitis-related pseudoaneurysms $[64,65]$. If the endovascular procedure is unsuccessful or if the clinical status is unstable, a surgical approach should be considered as the treatment option [64].

If occlusion of the donor artery is not appropriate, exclusion of the pseudoaneurysm from the circulation should be performed by securing the donor artery. To determine the acceptable treatment, neck size of the pseudoaneurysm guides the operator. If the pseudoaneurysm has a narrow neck, filling the sac with coils is preferred $[65,66]$. Embolization of the pseudoaneurysm itself by coils is achieved by advancing a catheter into the sac. Although this is the best option in narrow-necked pseudoaneurysms, there is a risk of recanalization due to the 

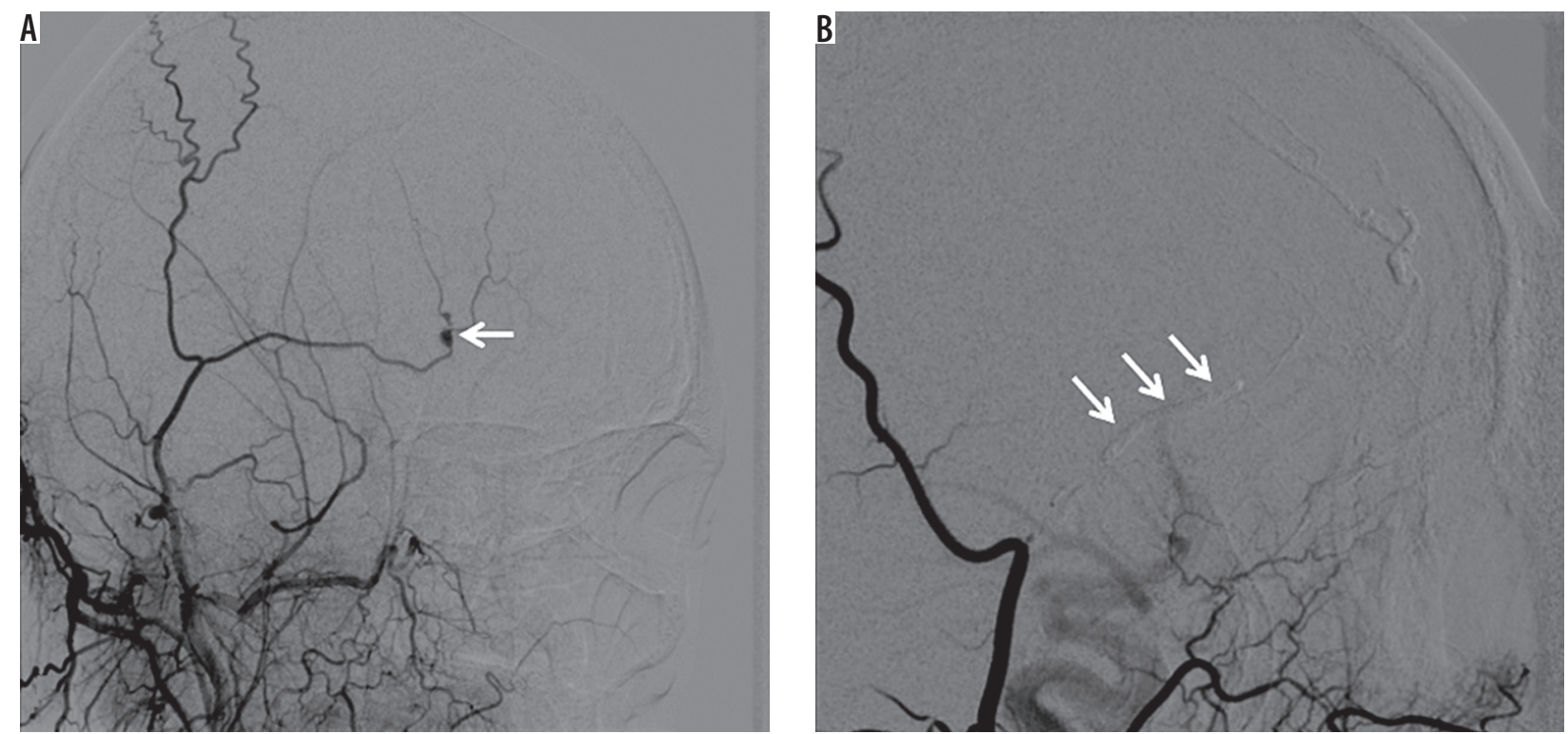

Figure 5. A) Selective right external carotid arteriogram demonstrates a pseudoaneurysm (arrow) of the superficial temporal artery after trauma. B) Embolization was performed with $30 \%$ glue and Lipiodol mixture (arrows)
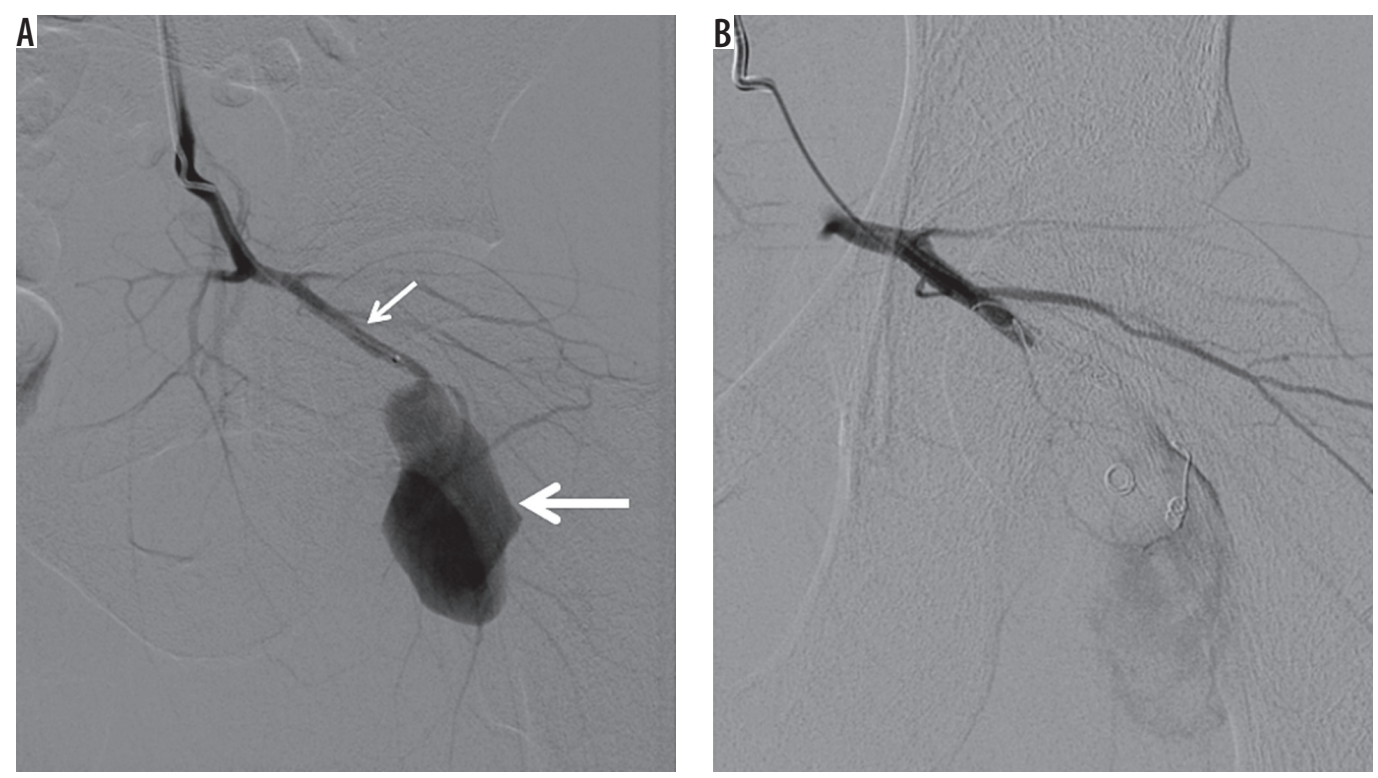

Figure 6. A 25 year-old man presented to the emergency department after being stabbed in the hip. A) Digital subtraction angiography shows a pseudoaneurysm (thick arrow) of the inferior gluteal artery (thin arrow). B) Exclusion of the pseudoaneurysm by means of distal and proximal coil embolization

nature of the coils. Nevertheless, soft helical coils handle this problem by packing the sac firmly [67]. In addition, thrombin and N-butyl 2-cyanoacrylate (glue) may help to embolize the pseudoaneurysmal sac.

In a wide-necked pseudoaneurysm, it is essential to secure the donor artery blood supply. Endovascular coiling of the sac with an uncovered stent placement is an option in this type of pseudoaneurysm. Besides this, covered stent implantation is an alternative choice in wide-necked pseudoaneurysms (Figure 8). Placement of covered stents should be performed in large-diameter and relatively smooth vessels due to the need of stiffer and larger systems. Also, thrombosis risk increases in small vessels. Because of these issues, vascular anatomy should be evaluated carefully in covered stent placement procedures.

Although technical and clinical success rates are similar between surgery and endovascular techniques, it is reported that endovascular management of pseudoaneurysms has lower morbidity rates [68]. Also, interventional radiological treatment options are performed under local anesthesia. This may prevent complications and long-time hospitalization due to general anesthesia.

\section{Conclusions}

The increase in the number of surgical and arteriographic procedures has caused higher prevalence of pseudo- 

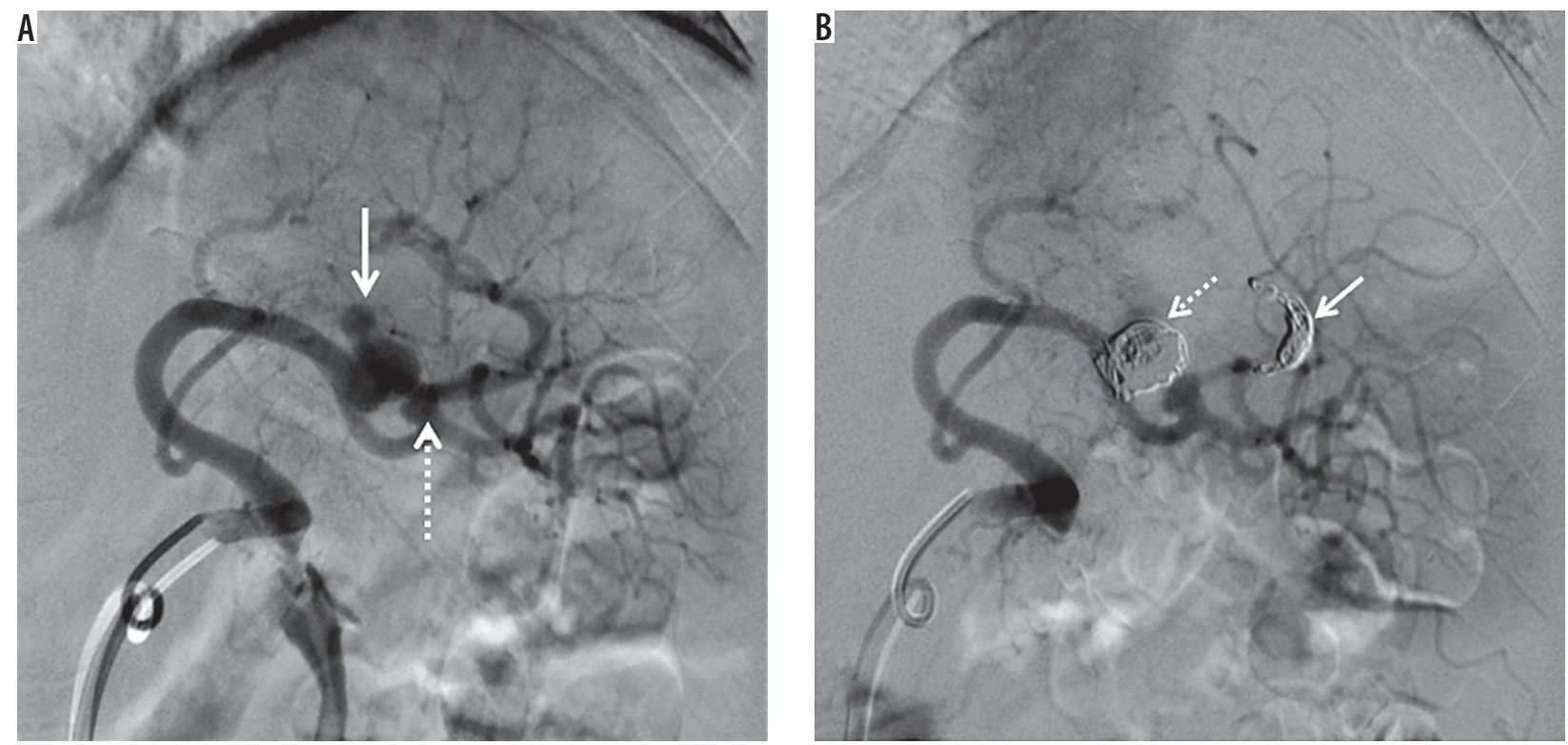

Figure 7. Splenic artery pseudoaneurysm caused by blunt abdominal trauma. A) Splenic arteriogram obtained before intervention shows two pseudoaneurysms (arrow and dotted arrow). B) Digital subtraction angiography demonstrates exclusion of the big pseudoaneurysm by distal coil embolization (arrow) and embolization of the pseudoaneurysm itself (dotted arrow). We decided to follow up the small pseudoaneurysm to protect the splenic blood flow
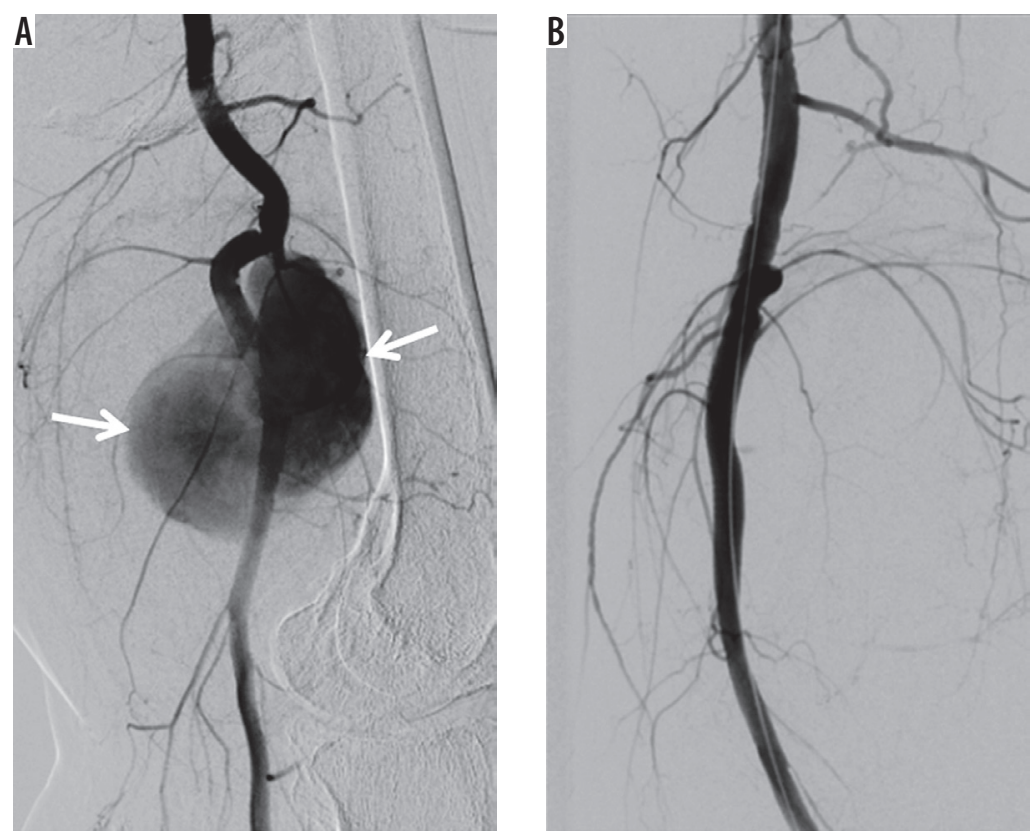

Figure 8. Covered stent placement. A) Digital subtraction angiography (DSA) shows a wide-necked pseudoaneurysm (arrows) of the popliteal artery. B) DSA demonstrates exclusion of the pseudoaneurysm using a covered stent

aneurysms recently. Diagnosis and optimal management are crucial due to the fact that pseudoaneurysms have life-threatening complications if not treated. Radiology offers alternative minimally invasive techniques that are associated with lower morbidity and mortality rates and have taken the place of surgery in the treatment.

\section{Ethical statement}

All procedures performed in studies involving human participants were in accordance with the ethical standards of the institutional and/or national research commit- tee and with the 1964 Helsinki Declaration and its later amendments or comparable ethical standards.

\section{Funding source}

The authors declared that this study has received no financial support.

\section{Disclosure}

The authors declare no conflicts of interest. 


\section{References}

1. Saad NE, Saad WE, Davies MG, et al. Pseudoaneurysms and the role of minimally invasive techniques in their management. Radiographics 2005; 25 Suppl 1: S173-189.

2. Munera F, Soto JA, Palacio D, et al. Diagnosis of arterial injuries caused by penetrating trauma to the neck: comparison of helical CT angiography and conventional angiography. Radiology 2000; 216: 356-362.

3. Kresowik TF, Khoury MD, Miller BV, et al. A prospective study of the incidence and natural history of femoral vascular complications after percutaneous transluminal coronary angioplasty. J Vasc Surg 1991; 13: 328-333.

4. Morgan R, Belli AM. Current treatment methods for postcatheterization pseudoaneurysms. J Vasc Interv Radiol 2003; 14: 697-710.

5. Arata MA, Cope C. Principles used in the management of visceral aneurysms. Tech Vasc Intervent Radiol 2000; 3: 124-129.

6. Hessel JS, Adams JF, Adams HL. Complications of angiography. Radiology 1981; 138: 273-281.

7. Brener BJ, Couch NP. Peripheral arterial complications on left heart catheterization and their management. Am J Surg 1973; 125: 521526.

8. Dzijan-Horn M, Langwieser N, Groha P, et al. Safety and efficacy of a potential treatment algorithm by using manual compression repair and ultrasound-guided thrombin injection for the management of iatrogenic femoral arterypseudoaneurysm in a large patient cohort. Circ Cardiovasc Interv 2014; 7: 207-215.

9. Tulsyan N, Kashyap VS, Greenberg RK, et al. The endovascular management of visceral artery aneurysms and pseudoaneurysms. J Vasc Surg 2007; 45: 276-283.

10. Cordova AC, Sumpio BE. Visceral artery aneurysms and pseudoaneurysms - should they all be managed by endovascular techniques? Ann Vasc Dis 2013; 6: 687-693.

11. Dror S, Dani BZ, Ur M, et al. Spontaneous thrombosis of a splenic pseudoaneurysm after blunt abdominal trauma. J Trauma 2002; 53: 383-385.

12. Oweida SW, Roubin GS, Smith RB, et al. Postcatheterization vascular complications associated with percutaneous transluminal coronary angioplasty. J Vasc Surg 1990; 12: 310-315.

13. Ahmad F, Turner SA, Torrie P, et al. Iatrogenic femoral artery pseudoaneurysms - a review of current methods of diagnosis and treatment. Clin Radiol 2008; 63: 1310-1316.

14. Ahmed A, Samuels SL, Keeffe EB, et al. Delayed fatal hemorrhage from pseudoaneurysm of the hepatic artery after percutaneous liver biopsy. Am J Gastroenterol 2001; 96: 233-237.

15. Okuno A, Miyazaki M, Ito H, et al. Nonsurgical management of ruptured pseudoaneurysm in patients with hepatobiliary pancreatic diseases. Am J Gastroenterol 2001; 96: 1067-1071.

16. Ferrero E, Viazzo A, Ferri M, et al. Management and urgent repair of ruptured visceral artery aneurysms. Ann Vasc Surg 2011; 25: 981. e7-11.

17. Coughlin BF, Paushter DM. Peripheral pseudoaneurysms: evaluation with duplex US. Radiology 1988; 168: 339-342.

18. Abu-Yousef MM, Weise JA, Shamma AR. The "to-and-fro" sign: duplex Doppler evidence of femoral artery pseudoaneurysm. AJR Am J Roentgenol 1988; 150: 632-634.
19. O'Sullivan GJ, Ray SA, Lewis JS, et al. A review of alternative approaches in the management of iatrogenic femoral pseudoaneurysms. Ann R Coll Surg Engl 1999; 81: 226-234.

20. Fellmeth BD, Roberts AC, Bookstein JJ, et al. Postangiographic femoral artery injuries: nonsurgical repair with US-guided compression. Radiology 1991; 178: 671-675.

21. La Perna L, Olin JW, Goines D, et al. Ultrasound-guided thrombin injection for the treatment of postcatheterization pseudoaneurysms. Circulation 2000; 102: 2391-2395.

22. Núñez D Jr, Rivas L, McKenney K, et al. Helical CT of traumatic arterial injuries. AJR Am J Roentgenol 1998; 170: 1621-1626.

23. LeBlang SD, Núñez D Jr. Noninvasive imaging of cervical vascular injuries. AJR Am J Roentgenol 2000; 174: 1269-1278.

24. Sethi V, Philips S, Fraser-Hill M. Lines and circles: pictorial review of cross-sectional imaging of active bleeding and pseudoaneurysm in the abdomen and pelvis. Can Assoc Radiol J 2013; 64: 36-45.

25. Busquets AR, Acosta JA, Colon E, et al. Helical computed tomographic angiography for the diagnosis of traumatic arterial injuries of the extremities. J Trauma 2004; 56: 625-628.

26. Rubin GD, Dake MD, Semba CP. Current status of three dimensional spiral CT scanning for imaging the vasculature. Radiol Clin North Am 1995; 33: 51-69.

27. Soto JA, Munera F, Cardoso N, et al. Diagnostic performance of helical CT angiography in trauma to large arteries of the extremities. J Comput Assist Tomogr 1999; 23: 188-196.

28. Soto JA, Munera F, Morales C, et al. Focal arterial injuries of the proximal extremities: helical CT arteriography as the initial method of diagnosis. Radiology 2001; 218: 188-194.

29. Miller-Thomas MM, West OC, Cohen AM. Diagnosing traumatic arterial injury in the extremities with CT angiography: pearls and pitfalls. Radiographics 2005; 25 Suppl 1: S133-142.

30. Rofsky NM, Adelman MA. MR angiography in the evaluation of atherosclerotic peripheral vascular disease. Radiology 2000; 214 : 325-338.

31. Popma JJ, Satler LF, Pichard AD, et al. Vascular complications after balloon and new device angioplasty. Circulation 1993; 88 (4 Pt 1): 1569-1578.

32. Tavakol M, Ashraf S, Brener SJ. Risks and complications of coronary angiography: a comprehensive review. Glob J Health Sci 2012; 4: 65-93.

33. Katzenschlager R, Ugurluoglu A, Ahmadi A, et al. Incidence of pseudoaneurysm after diagnostic and therapeutic angiography. Radiology 1995; 195: 463-466.

34. Raghavan A, Wong CK, Lam A, et al. Spontaneous occlusion of post-traumatic splenic pseudoaneurysm: report of two cases in children. Pediatr Radiol 2004; 34: 355-357.

35. Inoue $\mathrm{Y}$, Ikegawa $\mathrm{H}$, Ukai I, et al. Spontaneous occlusion of splenic and renal pseudoaneurysm after blunt abdominal trauma: a case report and literature review. J Emerg Med 2010; 38: e17-22.

36. Kent KC, McArdle CR, Kennedy B, et al. A prospective study of the clinical outcome of femoral pseudoaneurysm and arteriovenous fistulas induced by arterial puncture. J Vasc Surg 1993; 17: 125-133.

37. Toursarkissian B, Allen BT, Petrinec D, et al. Spontaneous closure of selected iatrogenic pseudoaneurysms and arteriovenous fistulae. J Vasc Surg 1997; 25: 803-808. 
38. Guillon R, Gracier JM, Abergel A, et al. Management of splenic artery aneurysms and false aneurysms with endovascular treatment in 12 patients. Cardiovasc Intervent Radiol 2003; 26: 256-260.

39. Tessier DJ, Stone WM, Fowl RJ, et al. Clinical features and management of splenic artery pseudoaneurysm: Case series and cumulative review of literature. J Vasc Surg 2003; 38: 969-974.

40. Ricci MA, Trevisani GT, Pilcher DB. Vascular complications of cardiac catheterization. Am J Surg 1994; 167: 375-378.

41. Lumsden AB, Miller JM, Kosinski AS, et al. A prospective evaluation of surgically treated groin complications following percutaneous cardiac procedures. Am Surg 1994; 60: 132-137.

42. Eisenberg L, Paulson EK, Kliewer MA, et al. Sonographically guided compression repair of pseudoaneurysms: further experience from a single institution. AJR Am J Roentgenol 1999; 173: 1567-1573.

43. Coley BD, Roberts AC, Fellmeth BD, et al. Postangiographic femoral artery pseudoaneurysms: further experience with US-guided compression repair. Radiology 1995; 194: 307-311.

44. Steinkamp HJ, Werk M, Felix R. Treatment of postinterventional pseudoaneurysms by ultrasound-guided compression. Invest Radiol 2000; 35: 186-192.

45. Middleton WD, Dasyam A, Teefey SA. Diagnosis and treatment of iatrogenic femoral artery pseudoaneurysms. Ultrasound Q 2005; 21: $3 \mathrm{e} 17$.

46. Zahn R, Thoma S, Fromm E, et al. Pseudoaneurysm after cardiac catheterization: therapeutic interventions and their sequelae: experience in 86 patients. Cathet Cardiovasc Diagn 1997; 40: 9-15.

47. Horn M, Stahlberg E, Goltz JP, et al. Management of Groin Pseudoaneurysms: Indications and Outcomes for Thrombin Injection vs. Surgical Treatment. Vasc Med Surg 2017; 5: 1.

48. Paulson EK, Nelson RC, Mayes CE, et al. Sonographically guided thrombin injection of iatrogenic femoral pseudoaneurysms: Further experience of a single institution. AJR Am J Roentgenol 2001; 177: 309-316.

49. Khoury M, Rebecca A, Greene K, et al. Duplex scanning-guided thrombin injection for the treatment of iatrogenic pseudoaneurysms. J Vasc Surg 2002; 35: 517-521.

50. Kang S, Labropoulos N, Mansour MA, et al. Percutaneous ultrasound guided thrombin injection: a new method for treating postcatheterization femoral pseudoaneurysms. J Vasc Surg 1998; 27: 1032-1038

51. Kang SS, Labropoulos N, Mansour MA, et al. Expanded indications for ultrasound-guided thrombin injection of pseudoaneurysms. J Vasc Surg 2000; 31: 289-298.

52. Sackett WR, Taylor SM, Coffey CB, et al. Ultrasound-guided thrombin injection of iatrogenic femoral artery pseudoaneurysms: a prospective analysis. Am Surg 2000; 66: 937-940.
53. Gale SS, Scissons RP, Jones L, et al. Femoral pseudoaneurysm thrombinjection. Am J Surg 2001; 181: 379-383.

54. Sadiq S, Ibrahim W. Thromboembolism complicating thrombin injection of femoral artery pseudoaneurysm: Management with intraarterial thrombolysis. J Vasc Interv Radiol 2001; 12: 633-636.

55. Pope M, Johnston KW. Anaphylaxis after thrombin injection of a femoral pseudoaneurysm: recommendations for prevention. J Vasc Surg 2000; 32: 190-191.

56. Matson MB, Morgan RA, Belli AM. Percutaneous treatment of pseudoaneurysms using fibrin adhesive. Br J Radiol 2001; 74: 690-694.

57. Weinmann EE, Chayen D, Kobzantzev ZV, et al. Treatment of postcatheterization false aneurysms: ultrasound-guided compression vs ultrasound-guided thrombin injection. Eur J Endovasc Surg 2002; 23: $68-72$.

58. Lemaire JM, Dondelinger RF. Percutaneous coil embolization of iatrogenic femoral arteriovenous fistula or pseudoaneurysm. Eur J Radiol 1994; 18: 96-100.

59. Thalhammer C, Kircherr AS, Uhlich F, et al. Postcatheterization pseudoaneurysms and arteriovenous fistulas: repair with percutaneous implantation of endovascular covered stents. Radiology 2000; 214: 127-131.

60. Lopez AJ, Buckenham TM. The radiological management of iatrogenic pseudoaneurysms. J Intervent Radiol 1996; 11: 133-143.

61. Sharma RP, Shetty PC, Burke TH, et al. Treatment of false aneurysm by using a detachable balloon. AJR Am J Roentgenol 1987; 149: 1279-1280.

62. Udd M, Leppäniemi AK, Bidel S, et al. Treatment of bleeding pseudoaneurysms in patients with chronic pancreatitis. World J Surg 2007; 31: 504-510.

63. de Perrot M, Berney T, Bühler L, et al. Management of bleeding pseudoaneurysms in patients with pancreatitis. Br J Surg 1999; 86: 29-32.

64. Chiang KC, Chen TH, Hsu JT. Management of chronic pancreatitis complicated with a bleeding pseudoaneurysm. World J Gastroenterol 2014; 20: 16132-16137.

65. Bergert H, Hinterseher I, Kersting S, et al. Management and outcome of hemorrhage due to arterial pseudoaneurysms in pancreatitis. Surgery 2005; 137: 323-328.

66. Yamakado K, Nakatsuka A, Tanaka N, et al. Transcatheter arterial embolization of ruptured pseudoaneurysms with coils and n-butyl cyanoacrylate. J Vasc Intervent Radiol 2000; 11: 66-72.

67. Krysl J, Kumpe D. Embolization agents: a review. Tech Vasc Intervent Radiol 2000; 3: 158-161.

68. Batagini NC, El-Arousy H, Clair DG, et al. Open versus Endovascular Treatment of Visceral Artery Aneurysms and Pseudoaneurysms. Ann Vasc Surg 2016; 35: 1-8. 